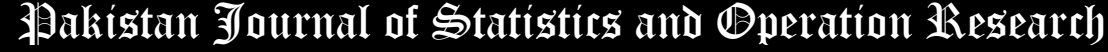

\section{A Generalization of Lomax Distribution with Properties, Copula and Real Data Applications}

\author{
Hanaa Elgohari ${ }^{1 *}$ and Haitham M. Yousof ${ }^{2}$
}

* Corresponding Author

1. Department of applied statistics, Faculty of commerce, Mansoura University, Egypt, hanaa_elgohary@mans.edu.eg

2. Department of Statistics, Mathematics and Insurance, Benha University, Benha, Egypt, haitham.yousof@fcom.bu.edu.eg

\begin{abstract}
A new generalization of Lomax distribution is derived and studied. Some of its useful properties are derived. A simple clayton copula is used to generate many bivariate and multivariate type models. We performed graphical simulations to assess the finite sample behavior of the estimations. The new model is employed in modelling three real data sets.
\end{abstract}

Key Words: Lomax Distribution; Copula; Kaplan-Meier; Maximum Likelihood; Simulation; Modeling; Applications; Real Data.

Mathematical Subject Classification: 62N01; 62N02; 62E10.

\section{Introduction}

The Lomax (Lx) distribution or Pareto type II (PaII) distribution was presented for modeling business failure data by Lomax (1954). The Lx distribution has found wide attention and applications in a variety of fields, for instance, biological sciences, actuarial science, income, wealth inequality, engineering, medical, engineering, lifetime and reliability modeling. It has been applied for modeling data obtained from income and wealth (see Harris (1968) and Asgharzadeh and Valiollahi (2011)), firm size (see Corbellini et al. (2007)), reliability and life testing (see Hassan and Al-Ghamdi (2009)). A random variable (RV) is said to have the Lomax distribution if its survival function (SF) is given by

$$
S_{\alpha}(y)=1-\Pi_{\alpha}(y)=\left.(1+y)^{-\alpha}\right|_{y \geq 0},
$$

where $\Pi_{\alpha}(y)=1-\left.(1+y)^{-\alpha}\right|_{y \geq 0}$ is the cumulative distribution function (CDF) of the standard Lx model and

$$
h_{\alpha}(y)=\left.\alpha(1+y)^{-\alpha-1}\right|_{y \geq 0},
$$

is the probability density function (PDF) of the standard Lx model, where $\alpha$ is the shape parameters. The PDF in (2) is a special case from the well-known Burr XII (BXII) model. Many useful details about the Lx model and its relationship with other models can be found in Burr (1942, 1968 and 1973), Lomax (1954), Burr and Cislak (1968), Harris (1968), Rodriguez (1977), Tadikamalla (1980). Cordeiro et al. (2016) investigated a new flexible class of continuous distributions called the generalized odd log-logistic-G (GOLL-G) family with only two extra shape parameters. In the research, we introduce a new version of the BXII model using the GOLL-G family called the generalized odd log-logistic Lx (GOLLLx). For an arbitrary baseline CDF $\Pi_{\underline{\Psi}}(y)$, the CDF of the GOLL-G family is given by

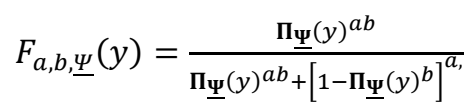

where $\underline{\Psi}$ is the parameter vector of the base line model. For $b=1$ we get the OLL-G family (Gleaton and Lynch (2006)). For $a=1$, the OLL-G family reduces to the proportional reversed hazard rate G (PRHR-G) family (Gupta and Gupta (2007)). The CDF of the GOLLLx is given by 


$$
F_{\underline{\Phi}}(y)=\frac{\left[1-(1+y)^{-\alpha}\right]^{a b}}{\left[1-(1+y)^{-\alpha}\right]^{a b}+\left\{1-\left[1-(1+y)^{-\alpha}\right]^{b}\right\}^{a}},
$$

where $\underline{\boldsymbol{\Phi}}=a, b, \alpha$. The PDF corresponding to (4) can be given as

$$
f_{\underline{\Phi}}(y)=\alpha a b(1+y)^{-\alpha-1} \frac{\left[1-(1+y)^{-\alpha}\right]^{a b-1}\left\{1-\left[1-(1+y)^{-\alpha}\right]^{b}\right\}^{a-1}}{\left(\left[1-(1+y)^{-\alpha}\right]^{a b}+\left\{1-\left[1-(1+y)^{-\alpha}\right]^{b}\right\}^{a}\right)^{2}} .
$$

The hazard rate function (HRF) for the GOLLLx model can be obtained from $h_{\Phi}(y)=f_{\underline{\Phi}}(y) /\left[1-F_{\underline{\Phi}}(y)\right]$. For $b=$ 1 we get the OLLLx model. For $a=1$ we get the PRHRLx model. Recently, many useful extensions are presented by Bhatti et al. (2018), Goual Yousof (2019), Ibrahim and Yousof (2020), Karamikabir et al. (2020), Mansour et al. (2020f), Ansari et al. (2020), Goual et al. (2020) and Yadav et al. (2020). Based on generalized binomial expansions and after some algebraic processes, the PDF in (6) can be rewritten as

where $\alpha^{*}=\alpha\left(1+\ell_{4}\right)$ and

$$
f_{\underline{\Phi}}(y)=\sum_{\ell_{4}=0}^{\infty} c_{\left[\ell_{4}\right]} h_{\alpha^{*}}(y)
$$

$$
c_{\left[\ell_{4}\right]}=\frac{a b}{1+\ell_{4}} \sum_{\ell_{1}, \ell_{2}=0}^{\infty} \sum_{\ell_{3}=\ell_{4}}^{\infty}(-1)^{\ell_{2}+\ell_{3}+\ell_{4}}\left(\begin{array}{c}
-2 \\
\ell_{1}
\end{array}\right)\left(\begin{array}{c}
\ell_{3} \\
\ell_{4}
\end{array}\right)\left(\begin{array}{c}
1+\ell_{3} \\
y
\end{array}\right)\left(\begin{array}{c}
-a\left(\ell_{1}+1\right) \\
\ell_{2}
\end{array}\right)\left(\begin{array}{c}
a b\left(\ell_{1}+1\right)+b \ell_{2}-1 \\
\ell_{3}
\end{array}\right) \text {, }
$$

and $h_{\alpha^{*}}(y)$ is the PDF of the Lx model with parameters $\alpha^{*}$. Accordingly, the PDF of the new model can be expressed as a linear mixture of the Lx PDF. So, many properties of the new Lx model can be derived from (6) and those of the standard Lx model. Let $Y$ be a RV having the Lx distribution (2) with parameter $a_{2}$. For $m<a_{2}$, the $m^{\text {th }}$ ordinary and incomplete moments (Ic-Ms) of $Y$ are, respectively, given by

where

$$
\mu_{m}^{\prime}=\alpha B(\alpha-m, 1+m) \text { and } \mathrm{I}_{m}(t)=\alpha B(t ; \alpha-m, 1+m)
$$

$$
\left.B\left(a_{1}, a_{2}\right)=\int_{0}^{\infty} 1+y\right)^{-\left(a_{1}+a_{2}\right)}\left(y^{a_{1}-1} d y \text { and } B\left(t ; a_{1}, a_{2}\right)=\int_{0}^{y}(1+y)^{-\left(a_{1}+a_{2}\right)} y^{a_{1}-1} d y\right.
$$

are the beta and the incomplete beta functions of the second type, respectively.
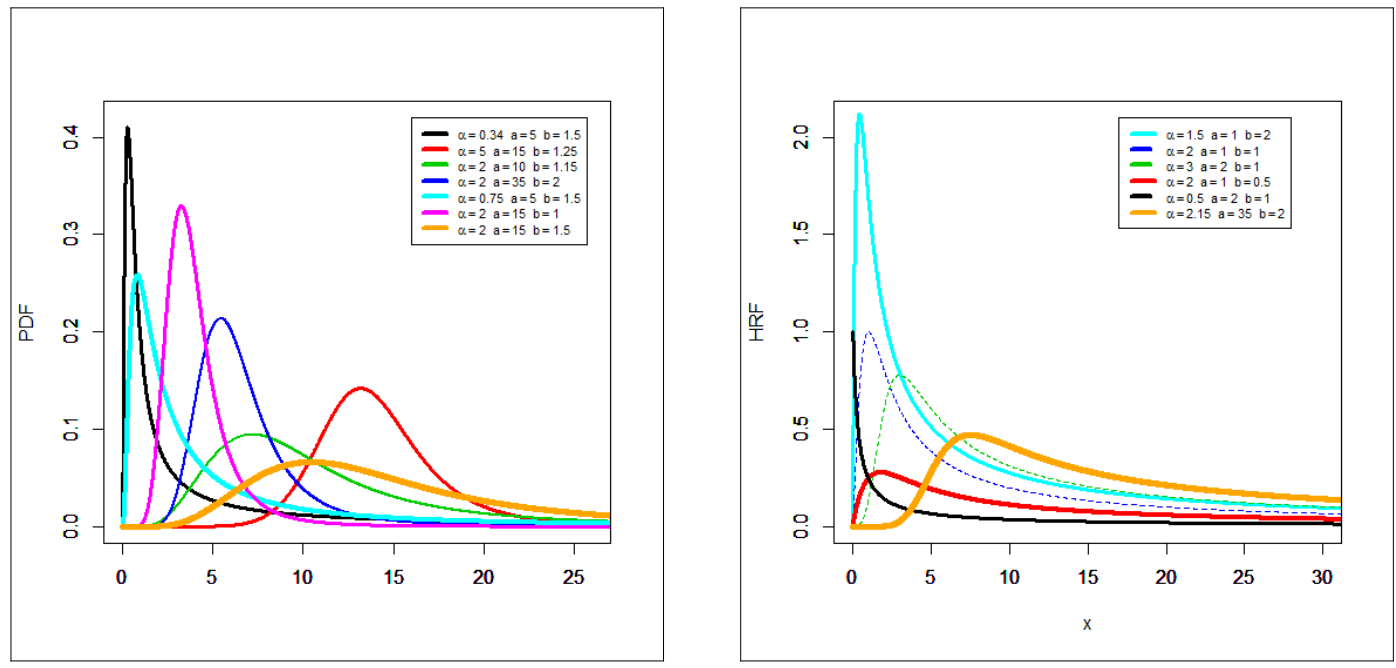

Figure 1: Plots for the new PDF and its corresponding HRF for some selected parameter values.

\section{Properties}

\subsection{Asymptotics}

Let $\varepsilon=\inf \left\{\left.Y\right|_{\left[\Pi_{\alpha}(y)>0\right]}\right\}$, the asymptotics of the CDF, PDF and HRF as $Y \rightarrow \varepsilon$ are given by

and

$$
\left.F_{\underline{\Phi}}(y)\right|_{y \rightarrow \varepsilon} \sim\left[1-(1+y)^{-\alpha}\right]^{a b},\left.f_{\underline{\Phi}}(y)\right|_{y \rightarrow \varepsilon} \sim \frac{\alpha a b(1+y)^{-\alpha-1}}{\left[1-(1+y)^{-\alpha}\right]^{-a b+1}}
$$

$$
\left.h_{\underline{\Phi}}(y)\right|_{y \rightarrow \varepsilon} \sim \frac{\alpha a b(1+y)^{-\alpha-1}}{\left\{1-(1+y)^{-\alpha}\right\}^{-a b+1}} \text {. }
$$


The asymptotics of CDF, PDF and HRF as $Y \rightarrow \infty$ are given by

\subsection{Ordinary moment}

$$
1-\left.F_{\underline{\Phi}}(y)\right|_{y \rightarrow \infty} \sim \frac{b^{a}}{(1+y)^{a \alpha}},\left.f_{\underline{\Phi}}(y)\right|_{y \rightarrow \infty} \sim \frac{a b^{a} \alpha}{(1+y)^{a \alpha+1}} \text { and }\left.h_{\underline{\Phi}}(y)\right|_{y \rightarrow \infty} \sim \frac{a \alpha}{1+y} .
$$

The $m^{\text {th }}$ ordinary moment of $Y$ is given by

$$
\mu_{m}^{\prime}=E\left(y^{m}\right)=\sum_{\ell_{4}=0}^{\infty} c_{\left[\ell_{4}\right]} \int_{0}^{\infty} y^{m} h_{\alpha^{*}}(y) d y
$$

Then,

$$
\mu_{m}^{\prime}=E\left(y^{m}\right)=\left.\sum_{\ell_{4}=0}^{\infty} c_{\left[\ell_{4}\right]} \alpha^{*} B\left(\alpha^{*}-m, 1+m\right)\right|_{\left(m<a \alpha^{*}\right)} .
$$

Setting $m=1$ in (7), we have the mean of $Y$. The effects of the parameters $a, b, \alpha$ on the mean $\left(\mu_{1}^{\prime}\right)$, variance $(\mathrm{V}(Y))$, skewness $(\mathrm{S}(Y))$ and kurtosis $(\mathrm{K}(Y))$ for given values are listed in Table 1. Form Tables 1 and 2 we note that the new additional shape parameters and has an effect on $\mu_{1}^{\prime}, \mathrm{V}(Y), \mathrm{S}(\mathrm{W})$ and $\mathrm{K}(Y)$. For the GOLLLx model, $\mathrm{S}(Y)$ can range in the interval $(-183.1,7514.7)$. However, for the Lx model, $\mathrm{S}(Y)$ can range in the interval $(-$ $0.4104,4.6476)$. For the GOLLLx model, $\mathrm{K}(Y)$ can range in the interval $(-1531.11,56479275)$. However, for the

\begin{tabular}{|c|c|c|c|c|c|c|}
\hline $\mathrm{a}$ & $\mathrm{b}$ & $\alpha$ & $\mu_{1}^{\prime}$ & $\mathrm{V}(\mathrm{Y})$ & $\mathrm{S}(\mathrm{Y})$ & $\mathrm{K}(\mathrm{Y})$ \\
\hline 1 & 10 & 5 & 0.8598479 & 0.326637100 & 3.6522880 & 50.47191 \\
\hline 2 & & & 0.7540910 & 0.055488670 & 1.6301880 & 9.990193 \\
\hline 5 & & & 0.7232649 & 0.007758169 & 0.6661556 & 5.150165 \\
\hline 10 & & & 0.7187439 & 0.001897504 & 0.3352351 & 4.442170 \\
\hline 25 & & & 0.7174704 & 0.000301686 & 0.1343592 & 4.239094 \\
\hline 40 & & & 0.7173224 & 0.000117759 & 0.0839946 & 4.215275 \\
\hline 50 & & & 0.7172882 & $7.535265 \times 10^{-5}$ & 0.0672000 & 4.209720 \\
\hline 60 & & & $4.871488 \times 10^{-5}$ & $3.725648 \times 10^{-5}$ & 125.43350 & 15750.29 \\
\hline 75 & & & $2.314250 \times 10^{-6}$ & $1.777331 \times 10^{-5}$ & 576.40470 & 332410.3 \\
\hline 80 & & & $8.330471 \times 10^{-7}$ & $6.403259 \times 10^{-7}$ & 961.01880 & 923925.1 \\
\hline 90 & & & $1.071033 \times 10^{-7}$ & $8.242558 \times 10^{-8}$ & 2681.3500 & 7191418 \\
\hline 100 & & & $1.364333 \times 10^{-8}$ & $1.050770 \times 10^{-8}$ & 7514.6940 & 5647926 \\
\hline \multirow[t]{17}{*}{3} & 0.01 & 5 & $1.358 \times 10^{-6}$ & $5.3288 \times 10^{-8}$ & 565.0617 & 617625.9 \\
\hline & 0.1 & & 0.001966 & $6.1993 \times 10^{-5}$ & 15.21565 & 471.3322 \\
\hline & 0.5 & & 0.070440 & 0.0025435 & 2.414007 & 15.80801 \\
\hline & 1 & & 0.160977 & 0.0056581 & 1.655923 & 9.734984 \\
\hline & 5 & & 0.519958 & 0.0163016 & 1.153708 & 7.010816 \\
\hline & 10 & & 0.733841 & 0.0226245 & 1.097702 & 6.769463 \\
\hline & 20 & & 0.984661 & 0.0306119 & 1.070302 & 6.655797 \\
\hline & 50 & & 1.378768 & 0.0448314 & 1.054058 & 6.589766 \\
\hline & 100 & & 1.730548 & 0.0594514 & 1.048677 & 6.568111 \\
\hline & 150 & & 1.960502 & 0.0700359 & 1.046887 & 6.560931 \\
\hline & 500 & & 2.765278 & 0.1136273 & 1.044384 & 6.550913 \\
\hline & 1000 & & 3.324861 & 0.1500068 & 1.043848 & 6.548771 \\
\hline & 3000 & & 4.387358 & 0.2328648 & 1.043491 & 6.547344 \\
\hline & 5000 & & 4.966800 & 0.2856750 & 1.043419 & 6.547059 \\
\hline & 7000 & & 5.382125 & 0.3268405 & 1.043389 & 6.546937 \\
\hline & 9000 & & 5.711093 & 0.3614103 & 1.043372 & 6.546869 \\
\hline & 10000 & & 5.854005 & 0.3769692 & 1.043366 & 6.546845 \\
\hline \multirow[t]{6}{*}{4} & 4 & 1.5 & 2.5216120 & 0.5909997000 & 2.0270130 & 17.48084 \\
\hline & & 3 & 0.8666202 & 0.0373406600 & 1.1463170 & 7.326794 \\
\hline & & 5 & 0.4524331 & 0.0078818440 & 0.8951852 & 5.88929 \\
\hline & & 10 & 0.2046185 & 0.0013274300 & 0.7275170 & 5.165168 \\
\hline & & 15 & 0.1320247 & 0.0005176865 & 0.6747110 & 4.972186 \\
\hline & & 20 & 0.0974268 & 0.0002728258 & 0.6488175 & 5.133086 \\
\hline
\end{tabular}
Lx model, $\mathrm{K}(Y)$ can range in the interval $(0.93244,73.8)$.

Table 1: Numerical results for $\mu_{1}{ }^{\prime}, \mathrm{V}(\mathrm{Y}), \mathrm{S}(\mathrm{Y}), \mathrm{K}(\mathrm{Y})$ for the GOLLLx. 


\begin{tabular}{ccccc}
25 & 0.0771908 & 0.0001679220 & 0.6334305 & -214.1473 \\
30 & 0.0639131 & 0.0001136188 & 0.6232612 & 792.5223 \\
35 & 0.0545320 & $8.193953 \times 10^{-5}$ & 0.615986 & -244.6907 \\
40 & 0.0475519 & $6.186782 \times 10^{-5}$ & -152.5364 & 2769.331 \\
45 & 0.0421557 & $4.835713 \times 10^{-5}$ & -98.06595 & 1620.058 \\
50 & 0.0378593 & $3.883173 \times 1-^{-5}$ & -34.64589 & 1206.973 \\
55 & 0.0343576 & $3.186594 \times 10^{-5}$ & 89.99558 & -585.3193 \\
60 & 0.0314487 & $2.661881 \times 10^{-5}$ & 129.3149 & -1531.107 \\
65 & 0.0289940 & $2.256758 \times 10^{-5}$ & 80.29819 & -1170.643 \\
75 & 0.0250788 & $1.681641 \times 10^{-5}$ & -134.3165 & 2622.245 \\
80 & 0.0234926 & $1.473220 \times 10^{-5}$ & -183.0836 & 3437.396 \\
\hline
\end{tabular}

Table 2: Numerical results for $\mu_{1}{ }^{\prime}, \mathrm{V}(\mathrm{Y}), \mathrm{S}(\mathrm{Y}), \mathrm{K}(\mathrm{Y})$ for the $\mathrm{Lx}$.

\begin{tabular}{ccccc}
\hline$\alpha$ & $\mu_{1}{ }^{\prime}$ & $\mathrm{V}(\mathrm{Y})$ & $\mathrm{S}(\mathrm{Y})$ & $\mathrm{K}(\mathrm{Y})$ \\
\hline 5 & 0.2500000 & 0.1041667 & 4.647580 & 73.8000 \\
10 & 0.1111111 & 0.0154321 & 2.811057 & 17.82857 \\
20 & 0.0526316 & 0.0030779 & 2.343806 & 12.13015 \\
50 & 0.0204082 & 0.0004339 & 2.126365 & 10.06002 \\
75 & 0.0135135 & 0.0001876 & 2.08269 & 9.684103 \\
100 & 0.0101010 & 0.0001041 & 2.059443 & 9.522699 \\
200 & 0.0050251 & $2.608252 \times 10^{-5}$ & 1.945802 & 8.349871 \\
300 & 0.0033445 & $1.038924 \times 10^{-5}$ & 2.956477 & 10.32769 \\
400 & 0.0025063 & $4.541270 \times 10^{-6}$ & 4.316849 & 22.29550 \\
500 & 0.0020040 & $2.703376 \times 10^{-6}$ & 3.090030 & 26.71821 \\
750 & 0.0013351 & $2.323909 \times 10^{-6}$ & -0.410385 & 3.747853 \\
1000 & 0.0010010 & $2.108303 \times 10^{-6}$ & -0.195204 & 0.932436 \\
1500 & 0.0006671 & $1.152765 \times 10^{-6}$ & 0.659860 & 1.406983 \\
2000 & 0.0005003 & $4.810577 \times 10^{-7}$ & 2.153126 & 4.878395 \\
\hline
\end{tabular}

\subsection{Moment generating function}

The moment generating function (MGF) of $Y$, say $M_{Y}(t)=E[\exp (t Y)]$, can be obtained from (6) as

$$
M_{Y}(t)=\sum_{\ell_{4}=0}^{\infty} c_{\left[\ell_{4}\right]} M_{\alpha^{*}}(t),
$$

where $M_{\alpha^{*}}(t)$ is the MGF of the Lx distribution with parameters $\alpha^{*}$. Then, we have

$$
M_{Y}(t)=\left.\sum_{\ell_{4}, r=0}^{\infty} \frac{t^{r}}{r !} c_{\left[\ell_{4}\right]} \alpha^{*} B\left(\alpha^{*}-m, 1+m\right)\right|_{\left(m<a \alpha^{*}\right)} .
$$

\subsection{Ic-Ms}

The $s^{\text {th }}$ Ic-M, say $I_{s}(q)$, of the GOLLLx distribution is given by $I_{s}(q)=\int_{0}^{q} y^{s} f(y) d y$. Then, from equation (7), we have $I_{s}(t)=\sum_{\ell_{4}=0}^{\infty} \quad c_{\left[\ell_{4}\right]} \int_{0}^{t} y^{s} h_{\alpha^{*}}(y) d y$ and using the lower incomplete gamma function, we obtain

$$
I_{s}(t)=\sum_{\ell_{4}=0}^{\infty} c_{\left[\ell_{4}\right]} \alpha^{*} B\left(t^{a} ; \alpha^{*}-s, 1+s\right) .
$$

The first Ic-M of $Y$, referred to $I_{1}(t)$, is just determined from the above equation by setting $s=1$. The first Ic-M has main applications related to the Bonferroni and Lorenz curves and the mean residual life and the mean waiting time. Moreover, the amount of scattering in a population is clearly measured, to some extent, by the totality of deviations from the mean and median. The mean deviations, about the mean and about the median of $Y$ depend on $I_{1}(t)$. The Bonferroni $\left[B_{Y, F(y), t}\right]$ and Lorenz $\left[L_{Y, t}\right]$ curves have many applications especially in deconomics, 
demography, insurance, reliability, medicine where $L_{Y, t}=\left.\frac{I_{(0, y)}(t)}{E(Y)}\right|_{\left(I_{(0, y)}(z)=\int_{0}^{y} \quad z f(z) d z\right)}$ and $B_{Y, F(y), t}=\frac{I_{(0, y)}(t)}{E(Y) F(y)}=$ $\frac{L_{Y, t}}{F(y)}$ where $F(y)=F_{\underline{\Phi}}(y)$. Then, we have

and

$$
L_{Y, t}=\left.\frac{\sum_{\ell_{4}=0}^{\infty} c_{\left[\ell_{4}\right]} \alpha^{*} B\left(t^{a} ; \alpha^{*}-s, 1+s\right)}{\sum_{\ell_{4}=0}^{\infty} c_{\left[\ell_{4}\right]} \alpha^{*} B\left(\alpha^{*}-s, 1+s\right)}\right|_{\left(s<a \alpha^{*}\right)}
$$

$$
B_{Y, F(y), t}=\left.\left(1+\frac{\left\{1-\left[1-(1+y)^{-\alpha}\right]^{b}\right\}^{a}}{\left[1-(1+y)^{-\alpha}\right]^{a b}}\right) \frac{\sum_{\ell_{4}=0}^{\infty} c_{\left[\ell_{4}\right]} \alpha^{*} B\left(t^{a} ; \alpha^{*}-s, 1+s\right)}{\sum_{\ell_{4}=0}^{\infty} c_{\left[\ell_{4}\right]} \alpha^{*} B\left(\alpha^{*}-s, 1+s\right)}\right|_{\left(s<a \alpha^{*}\right)} .
$$

\subsection{Residual and reversed residual life functions}

The $m^{\text {th }}$ moment of the residual life (RL), denoted by $u_{m}(t)=\left.E\left[(Y-t)^{m}\right]\right|_{(Y>t, m=1,2, \ldots)}$. The $m^{\text {th }}$ moment of the residual life of $Y$ is given by $u_{m}(t)=\frac{\int_{t}^{\infty}(Y-t)^{m} f_{\Phi}(y) d y}{1-F_{\Phi}(t)}$. Then, we can write

$$
u_{m}(t)=\frac{1}{1-F_{\underline{\Phi}}(t)} \sum_{i=0}^{m} \sum_{\ell_{4}=0}^{\infty} \frac{(-1)^{m-i} m ! t^{m-i}}{i ! \Gamma(m-i+1)} c_{\left[\ell_{4}\right]} \alpha^{*} B\left(t^{a} ; \alpha^{*}-m, 1+m\right) .
$$

The $m^{\text {th }}$ moment reversed residual life, say $U_{m}(t)=\left.E\left[(t-Y)^{m}\right]\right|_{(t>0, Y \leq t \text { and } m=1,2, \ldots)}$. Then, $U_{m}(t)$ is defined by $U_{m}(t)=\frac{\int_{0}^{t}(t-Y)^{m} f_{\Phi}(y) d y}{F_{\underline{\Phi}}(t)}$. The $m^{\text {th }}$ moment of the reversed residual life of $Y$

$$
U_{m}(t)=\frac{1}{F_{\underline{\Phi}}(t)} \sum_{i=0}^{m} \sum_{\ell_{4}=0}^{\infty} \frac{(-1)^{i} m !}{i !(m-i) !} c_{\left[\ell_{4}\right]} \alpha^{*} B\left(t^{a} ; \alpha^{*}-m, 1+m\right) .
$$

\section{Maximum likelihood method}

Suppose that $\left(y_{1}, \cdots, y_{m}\right)$ is a random sample (rs) from the GOLLLx model with parameter vector $\underline{\boldsymbol{\Psi}}$. The $\log$ likelihood function $\left(\ell_{m}(\underline{\Psi})\right)$ for $\underline{\Psi}$ is given by

$$
\begin{aligned}
& \ell_{m}(\Psi)=m \log (\alpha a b)-(\alpha+1) \sum_{i=1}^{m} \log \left(y_{i}+1\right)+(a b-1) \sum_{i=1}^{m} \log \left(1-s_{i}^{-\alpha}\right) \\
& +(a-1) \sum_{i=1}^{m} \log \left(1-z_{i}^{b}\right)-2 \sum_{i=1}^{m} \log \left[z_{i}^{a b}+\left(1-z_{i}^{b}\right)^{a}\right] .
\end{aligned}
$$

where $s_{i}=\left(y_{i}+1\right)$ and $z_{i}=\left[1-s_{i}^{-\alpha}\right]$. The above $\ell_{m}(\underline{\Psi})$ can be maximized numerically via SAS (PROC NLMIXED) or R (optim) or Ox program (via sub-routine MaxBFGS), among others.

\section{Copula}

We derive some new bivariate type GOLLLx (BGOLLLx) model using "Farlie Gumbel Morgenstern" (FGM) Copula (see Morgenstern (1956), Gumbel (1958) and Gumbel (1960))," Clayton Copula", "modified FGM" and "Renyi's entropy" (Pougaza and Djafari (2011)). However, future works may be allocated to study these new models. First, we consider the joint CDF of the FGM family, where $C_{\Omega}(u, d)=\left.u \psi\left(1+\Omega u^{*} d^{*}\right)\right|_{u^{*}=1-u}$, where the marginal function $u=F_{1}, d=F_{2}, \boldsymbol{\Omega} \in(-1,1)$ is a dependence parameter and for every $u, \psi \in(0,1), C(u, 0)=C(0, \psi)=0$ which is "grounded minimum" and $C(u, 1)=u$ and $C(1, d)=d$ which is "grounded maximum", $C\left(u_{1}, d_{1}\right)+C\left(u_{2}, d_{2}\right)-$ $C\left(u_{1}, d_{2}\right)-C\left(u_{2}, d_{1}\right) \geq 0$.

\subsection{BGOLLLx type via FGM Copula}

A Copula is continuous in $u$ and $d$; actually, it satisfies the "stronger Lipschitz condition", where

For $0 \leq u_{1} \leq u_{2} \leq 1$ and $0 \leq \psi_{1} \leq \psi_{2} \leq 1$, we have

$$
\left|C\left(u_{2}, d_{2}\right)-C\left(u_{1}, d_{1}\right)\right| \leq\left|u_{2}-u_{1}\right|+\left|d_{2}-d_{1}\right| .
$$

$$
C\left(u_{1}, d_{1}\right)+C\left(u_{2}, d_{2}\right)-C\left(u_{1}, d_{2}\right)-C\left(u_{2}, d_{1}\right)=\operatorname{Pr}\left(u_{1} \leq U \leq u_{2}, d_{1} \leq D \leq d_{2}\right) \geq 0 .
$$

Then, setting $u^{*}=1-\left.F_{\underline{\Psi}_{1}}\left(x_{1}\right)\right|_{\left[u^{*}=(1-u) \in(0,1)\right]}$ and $d^{*}=1-\left.F_{\underline{\Psi}_{2}}\left(x_{2}\right)\right|_{\left[d^{*}=(1-d) \in(0,1)\right]}$. We can esaily get the get the joint CDF of the FGM family. The joint PDF can then derived from $c_{\boldsymbol{\Omega}}(u, \psi)=1+\left.\boldsymbol{\Omega} u^{\prime} d^{\prime}\right|_{\left(u^{\prime}=1-2 u \text { and } d^{\prime}=1-2 d\right)}$ or from $f\left(x_{1}, x_{2}\right)=C\left(F_{\underline{\Psi}_{1}}\left(x_{1}\right)_{1}, F_{\underline{\Psi}_{2}}\left(x_{2}\right)\right) f_{\underline{\Psi}_{1}}\left(x_{1}\right)_{1}, f_{\underline{\Psi}_{2}}\left(x_{2}\right)$. 


\subsection{BGOLLLx and MvGOLLLx type via Clayton Copula}

The "Clayton Copula" can be considered as $C_{\Omega}\left(d_{1}, d_{2}\right)=\left.\left[\left(1 / d_{1}\right)^{\Omega}+\left(1 / d_{2}\right)^{\Omega}-1\right]^{-\Omega^{-1}}\right|_{\nabla \in(0, \infty)}$. Setting $d_{1}=$ $F_{\underline{\Psi}_{1}}(t)$ and $d_{2}=F_{\underline{\Psi}_{2}}(x)$. Then, the BGOLLLx type can be derived from $C\left(d_{1}, d_{2}\right)=C\left(F_{\underline{\Psi}_{1}}(t), F_{\underline{\Psi}_{2}}(x)\right)$. Similarly, the MGOLLLx ( $m$-dimensional extension) from the above can be derived from $C\left(d_{i}\right)=\left[\sum_{i=1}^{m} d_{i}^{-\Omega}+1-m\right]^{-\Omega^{-1}}$.

\subsection{BGOLLLx type via Renyi's entropy}

Using the theorem of Pougaza and Djafari (2011) where $R(u, d)=x_{2} u+x_{1} d-x_{1} x_{2}$. Then, the associated BGOLLLx will be $R(u, d)=R\left(F_{\Psi_{1}}\left(x_{1}\right), F_{\Psi_{2}}\left(x_{2}\right)\right)$.

\subsection{BGOLLLx type via modified FGM Copula}

The modified version of the bivariate FGM copula defined as (Rodriguez-Lallena and Ubeda-Flores (2004)) $C_{\boldsymbol{\Omega}}(u, d)=u d+\boldsymbol{\Omega} \widetilde{\mathbf{0}(u)} \widetilde{\boldsymbol{\psi}(d)}$, where $\widetilde{\mathbf{0}(u)}=u \overline{\mathbf{0}(u)}$, and $\overline{\boldsymbol{\psi}(d)}=d \overline{\mathbf{0}(d)}$. Where $\mathbf{0}(u)$ and $\boldsymbol{\Psi}(v)$ are two continuous functions on $(0,1)$ where $\mathbf{O}(0)=\mathbf{O}(1)=\boldsymbol{\psi}(0)=\boldsymbol{\psi}(1)=0$. Let

$$
\begin{aligned}
& b=\inf \left\{\frac{\partial}{\partial u} \widetilde{\mathbf{O}(u)}: \mathcal{H}_{1}(u)\right\}<0, a=\sup \left\{\frac{\partial}{\partial u} \widetilde{\mathbf{O}(u)}: \mathcal{H}_{1}(u)\right\}<0, \\
& c=\inf \left\{\frac{\partial}{\partial \psi} \widetilde{\boldsymbol{\Psi}(d)}: \mathcal{H}_{2}(d)\right\}>0, s=\sup \left\{\frac{\partial}{\partial \psi} \widetilde{\boldsymbol{\Psi}(d)}: \mathcal{H}_{2}(d)\right\}>0 .
\end{aligned}
$$

Then, $\min (b a, c s) \geq 1$, where $\frac{\partial}{\partial u} \widetilde{\mathbf{0}(u)}=\mathbf{O}(u)+u \frac{\partial}{\partial u} \mathbf{0}(u), \mathcal{H}_{1}(u)=\left\{u \in(0,1): \frac{\partial}{\partial u} \widetilde{\mathbf{0}(u)}\right.$ exists $\}$ and $\mathcal{H}_{2}(d)=$ $\left\{d \in(0,1): \frac{\partial}{\partial \psi} \widetilde{\boldsymbol{\Psi}(d)}\right.$ exists $\}$.

\subsubsection{BGOLLLx-FGM (Type I)}

The BivGOLLLx-FGM (Type-I) copula can be obtained directly from $C_{\boldsymbol{\Omega}}(u, v)=u \psi+\boldsymbol{\Omega} \widetilde{\boldsymbol{\phi}(u)} \widetilde{\boldsymbol{\Psi}(\psi)}$.

\subsubsection{BGOLLLX-FGM (Type II)}

Consider the following functional form for both $\mathbf{O}(u)$ and $\boldsymbol{\psi}(\psi)$ which satisfy all the conditions stated earlier where $\left.\mathbf{O}(u)\right|_{\left(\Omega_{1}>0\right)}=u^{\Omega_{1}}(1-u)^{1-\Omega_{1}}$ and $\left.\boldsymbol{\psi}(d)\right|_{\left(\Omega_{2}>0\right)}=d^{\Omega_{2}}(1-d)^{1-\Omega_{2}}$. The corresponding bivariate copula (henceforth, BGOLLLx-FGM (Type-II) copula) can be derived from

\subsubsection{BGOLLLx-FGM (Type III)}

$$
C_{\Omega, \Omega_{1}, \Omega_{2}}(u, d)=u d\left[1+\Omega u^{\Omega_{1}} d^{\Omega_{2}}(1-u)^{1-\Omega_{1}}(1-d)^{1-\Omega_{2}}\right] .
$$

Consider the following functional form for both $\mathbf{O}(u)$ and $\boldsymbol{\psi}(\psi)$ which satisfy all the conditions stated earlier where $\mathbf{0}^{\bullet}(u)=u[\log (1+\bar{u})]$ and $\boldsymbol{\Psi}^{\bullet}(d)=d[\log (1+\bar{d})]$. Then, the associated CDF of the BivGOLLLx-FGM (TypeIII)

\subsubsection{BGOLLLx-FGM (Type IV)}

$$
C_{\mathbf{\Omega}}(u, d)=u d+\left[1+\mathbf{\Omega O}^{\bullet}(u) \boldsymbol{\Psi}^{\bullet}(d)\right]
$$

The BGOLLLX-FGM (Type-IV) model can be derived from $C(u, d)=u F^{-1}(d)+d F^{-1}(u)-$ $F^{-1}(u) F^{-1}(d)$ where $F^{-1}(u)$ and $F^{-1}(d)$ can be easily derived.

\section{Graphical simulations}

To assess of the finite sample behavior of the MLEs, consider the following algorithm:

1) use $y_{u}=\left(1-\left[\frac{\left(\frac{u}{1-u}\right)^{\frac{1}{a}}}{1+\left(\frac{u}{1-u}\right)^{\frac{1}{a}}}\right]^{\frac{1}{b}}\right)^{-\frac{1}{\alpha}}-1$ to generate 1000 samples of size $m$ from the GOLLLx distribution;

2) compute the MLEs for the 1000 samples

3) compute the SEs of the MLEs for the 1000 samples. The standard errors (SEs) were computed by inverting the observed information matrix;

4) compute the biases $\left(B_{h}(m)\right)$ and mean squared errors (MSEs) given for $h=\underline{\boldsymbol{\Phi}}$. We repeated these steps for $m=50,100, \ldots, 1000$ with $\alpha=1, a=1, b=1,=1$ so computing biases, mean squared errors $\left(M S E_{h}(m)\right)$ for $\underline{\Phi}$ and $m=50,100, \ldots, 1000$. 


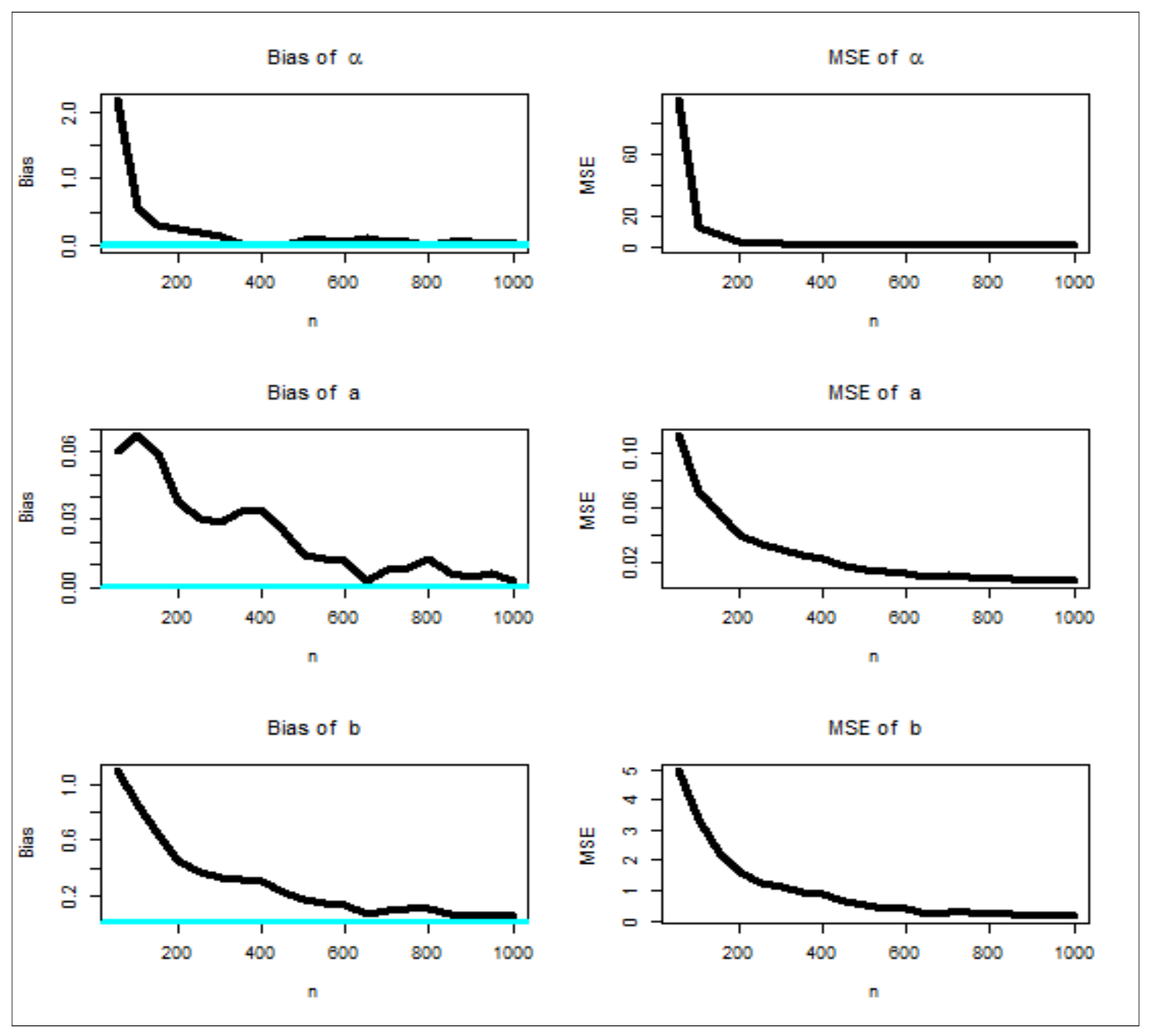

Figure 2: Biases and MSEs for $a, b, \alpha$ and $m=50,100, \ldots, 1000$ for the GOLLLx model.

Figure 2 (left panel) shows how the three biases vary with respect to $m$. Figure 2 (right panel) shows how the three MSEs vary with respect to $m$. The broken lines in Figure 2 corresponds to the biases being 0 . From Figure 2, the biases for each parameter decrease to zero as $m \rightarrow \infty$, the MSEs for each parameter decrease to zero as $m \rightarrow \infty$.

\section{Comparing models}

To illustrate the flexibility of the GOLLLx model, we provide three applications. The $1^{\text {st }}$ data set called breaking stress data. This data set consists of 100 observations of breaking stress of carbon fibrrs (in Gba) given by Nichols and Padgett (2006). The $2^{\text {nd }}$ data set called survival times. In this application, we work with the survival times (in days) of 72 guinea pigs infected with virulent tubercle bacilli, originally observed and reported by Bjerkedal, T. (1960). The $3^{\text {rd }}$ data set called taxes revenue data. The actual taxes revenue data (in 1000 million Egyptian pounds) given in Altun et al. (2018a, b). For all data sets, we compare the GOLLLx distribution with the standard Lx, the exponentiated Lx (ExpLx), the Burr XII (BXII), the Marshall-Olkin Burr XII (MOBXII), the Topp-Leone Burr XII (TLBXII), the Zografos-Balakrishnan Burr XII (ZBBXII), the five-parameters beta Burr XII (FBBXII), beta Burr XII (BBXII), beta exponentiated Burr XII (BEBXII), the five-parameters Kumaraswamy Burr XII (FKumBXII) and Kumaraswamy Burr XII (KumBXII) distributions. All competitive models are given in Yousof et al. (2019) and Altun et al. (2018 a, b). 
We consider the well-known G-O-F statistics: the Akaike Information Criterion (C - AI), Bayesian Information Criterion ( C - Bayes), Hannan-Quinn Information Criterion ( C - HQ), Consistent Akaike Information Criterion (C - CA) . Tables 3, 4 and 5 gives the MLEs, standard errors (SEs), confidence interval (CL) for the data set I, II, III respectively. Tables 6, 7 and 8 gives $\mathrm{C}-\mathrm{AI}, \mathrm{C}$-Bayes, C-HQ and C - CA values for the data set I, II, III respectively. It is noted that, for breaking stress data: $\mathrm{C}-\mathrm{AI}=301.44, \mathrm{C}-$ Bayes $=309.26, \mathrm{C}-\mathrm{AI}=301.69, \mathrm{C}-$ $\mathrm{HQ}=304.61$. For survival times guinea pigs: $\mathrm{C}-\mathrm{AI}=204.05, \mathrm{C}-$ Bayes $=210.88, \quad \mathrm{C}-\mathrm{CA}=206.77, \quad ?{ }_{\mathrm{HQ}}=$ 204.405. For the Egyptian tax's revenue data: $\mathrm{C}-\mathrm{AI}=384.12, \mathrm{C}-$ Bayes $=390.35, \mathrm{C}-\mathrm{CA}=386.55, \mathrm{C}-\mathrm{HQ}=$ 384.56. From 1, 2 and 3 we conclude that the new model has the lowest C - AI , C - Bayes , C - CA, C - HQ for all data sets. Figure 3 gives the TTT plots. Based on Figure 3, the HRF of the three real data sets are increasing. Figure 4 gives the estimated PDFs. Figure 5 gives the estimated CDFs. Figure 6 gives the estimated HRFs. Figure 7 gives the P-P plots. Figure 8 gives Kaplan-Meier survival Plot. Based on Figures 4-8 the GOLLLx model has adequate fits to the empirical functions. Based on the values in Tables 6, 7, 8 and Figures 4-8 the GOLLLx model has the best fits as compared to BXII other models in the three applications with small values for C-AI, C-Bayes, C-CA and C-HQ. Many useful real data can be found in Mansour et al. (2020a-f), Elsayed and Yousof (2019a,b,c and 2020), Elbiely and Yousof (2018 and 2019), Yousof et al. (2018a,b,c), Cordeiro et al. (2018), Gad et al. (2018), Hamedani et al. (2019), Ibrahim et al. (2019 and 2020), Korkmaz et al. (2017 and 2018 and 2019) and Merovci (2017).

Table 3: MLEs, SEs and CIs for the data set $\mathbf{I}$.

\begin{tabular}{|c|c|c|}
\hline Model & & $\mathrm{a}, \mathrm{b}, \alpha, \theta, \gamma$ \\
\hline \multirow[t]{3}{*}{$\mathrm{Lx}$} & MLEs & $---,---,---, 0.8025,---$ \\
\hline & SEs & $---,---,---,(0.08025),---$ \\
\hline & CIs & $---,---,---,(0.64,0.96),---$ \\
\hline \multirow[t]{3}{*}{ ExpLx } & MLEs & $---,---, 0.6437,0.767,---$ \\
\hline & SEs & $---,---,(0.0603),(0.094),---$ \\
\hline & CIs & $---,---,(0.48,0.72),(0.59),---$ \\
\hline \multirow[t]{3}{*}{ BXII } & MLEs & $---,---, 5.941,0.187,---$ \\
\hline & SEs & $---,--,(1.279),(0.044),---$ \\
\hline & CIs & $---,---,(3.43,8.45),(0.10,0.27),---$ \\
\hline \multirow[t]{3}{*}{ MOBXII } & MLEs & $---,--, 1.192,4.834,838.73$ \\
\hline & SEs & $---,---,(0.952),(4.896),(229.34)$ \\
\hline & CIs & $---,--, 0,3.06),(0,14.43),(389.22,1288.24)$ \\
\hline \multirow[t]{3}{*}{ TLBXII } & MLEs & ---,---, 1.350,1.061,13.728 \\
\hline & SEs & ---,--, 0.378$),(0.384),(8.400)$ \\
\hline & CIs & $---,--,(0.61,2.09),(0.31,1.81),(0,30.19)$ \\
\hline \multirow[t]{3}{*}{ KumBXII } & MLEs & $48.103,79.516,0.351,2.730,---$ \\
\hline & SEs & ----, (1.077), (0.098), (58.186), (19.348) \\
\hline & CIs & ---- \\
\hline \multirow[t]{3}{*}{ BBXII } & MLEs & $359.683,260.097,0.175,1.123,---$ \\
\hline & SEs & $(57.941),(132.213),(0.013),(0.243),---$ \\
\hline & CIs & $(246.1,473.2),(0.96,519.2),(0.14,0.20),(0.65,1.6),---$ \\
\hline \multirow[t]{3}{*}{ BEBXII } & MLEs & $0.381,11.949,0.937,33.402,1.705$ \\
\hline & SEs & $(0.078),(4.635),(0.267),(6.287),(0.478)$ \\
\hline & CIs & $(0.23,0.53),(2.86,21),(0.41,1.5),(21,45),(0.8,2.6)$ \\
\hline \multirow[t]{3}{*}{ FBBXII } & MLEs & $0.421,0.834,6.111,1.674,3.450$ \\
\hline & SEs & $(0.011),(0.943),(2.314),(0.226),(1.957)$ \\
\hline & CIs & $(0.4,0.44),(0.2 .7),(1.57,10.7),(1.23,2.1),(0,7)$ \\
\hline \multirow[t]{3}{*}{ FKumBXII } & MLEs & $0.542,4.223,5.313,0.411,4.152$ \\
\hline & SEs & $(0.137),(1.882),(2.318),(0.497),(1.995)$ \\
\hline & CIs & $(0.3,0.8),(0.53,7.9),(0.9,9),(0,1.7),(0.2,8)$ \\
\hline \multirow[t]{3}{*}{ ZBBXII } & MLEs & $123.101,---, 0.368,139.247,---$ \\
\hline & SEs & $(243.011),---,(0.343),(318.546),---$ \\
\hline & CIs & $(0,599.40),---,(0,1.04),(0,763.59),---$ \\
\hline \multirow[t]{3}{*}{ GOLLLx } & MLEs & $5.013,1.036,0.576,------$ \\
\hline & SEs & $(3.137),(1.046),(0.569),---,--$ \\
\hline & CIs & $(3.137),(1.046),(0.569),---,--$ \\
\hline
\end{tabular}


Table 4: MLEs, SEs and CIs for the data set II.

\begin{tabular}{|c|c|c|}
\hline Model & & $\mathrm{a}, \mathrm{b}, \alpha, \theta, \gamma$ \\
\hline \multirow[t]{3}{*}{$\mathrm{Lx}$} & MLEs &,--- ---, ---, $1.0244,---$ \\
\hline & SEs & $---,---,---,(0.1207),---$ \\
\hline & CIs & $---,---,---,(0.78,1.26),---$ \\
\hline \multirow[t]{3}{*}{ ExpLx } & MLEs & $---,---, 0.8257,0.9739,---$ \\
\hline & SEs & $---,---,(0.093),(0.1292),---$ \\
\hline & CIs & $---,---,(0.62,0.98),(0.64,1.16),---$ \\
\hline \multirow[t]{3}{*}{ BXII } & MLEs & $---,---, 3.102,0.465,---$ \\
\hline & SEs & $---,---,(0.538),(0.077),---$ \\
\hline & CIs & $---,---,(2.05,4.16),(0.31,0.62),---$ \\
\hline \multirow[t]{3}{*}{ MOBXII } & MLEs & $---,---, 2.259,1.533,6.760$ \\
\hline & SEs & $---,---,(0.864),(0.907),(4.587)$ \\
\hline & CIs & $---,---,(0.57,3.95),(0,3.31),(0,15.75)$ \\
\hline \multirow{3}{*}{ TLBXII } & MLEs & ---, ---, 2.393,0.458,1.796 \\
\hline & SEs & $---,---,(0.907),(0.244),(0.915)$ \\
\hline & CIs & $---,---,(0.62,4.17),(0,0.94),(0.002,3.59)$ \\
\hline \multirow[t]{3}{*}{ KumBXII } & MLEs & $14.105,7.424,0.525,2.274,---$ \\
\hline & SEs & $(10.805),(11.850),(0.279),(0.990),---$ \\
\hline & CIs & $(0,35.28),(0.30 .65),(0,1.07),(0.33,4.21),---$ \\
\hline \multirow[t]{3}{*}{ BBXII } & MLEs & $2.555,6.058,1.800,0.294,---$ \\
\hline & SEs & $(1.859),(10.391),(0.955),(0.466),---$ \\
\hline & CIs & $(0,6.28),(0,26.42),(0,3.67),(0,1.21),---$ \\
\hline \multirow[t]{3}{*}{ BEBXII } & MLEs & $1.876,2.991,1.780,1.341,0.572$ \\
\hline & SEs & $(0.094),(1.731),(0.702),(0.816),(0.325)$ \\
\hline & CIs & $(1.7,2.06),(0,6.4),(0.40,3.2),(0,2.9),(0,1.21)$ \\
\hline \multirow[t]{3}{*}{ FBBXII } & MLEs & $0.621,0.549,3.838,1.381,1.665$ \\
\hline & SEs & $(0.541),(1.011),(2.785),(2.312),(0.436)$ \\
\hline & CIs & $(0,1.7),(0,2.5),(0,9.3),(0,5.9),(0.8,4.5)$ \\
\hline \multirow[t]{3}{*}{ FKumBXII } & MLEs & $0.558,0.308,3.999,2.131,1.475$ \\
\hline & SEs & $(0.442),(0.314),(2.082),(1.833),(0.361)$ \\
\hline & CIs & $(0,1.4),(0,0.9),(0,3.1),(0,5.7),(0.76,2.2)$ \\
\hline \multirow[t]{3}{*}{ GOLLLx } & MLEs & $4.226,0.663,0.464,---,--$ \\
\hline & SEs & $(3.177),(0.701),(0.641),---,--$ \\
\hline & CIs & $(0,10.4),(0,2.06),(0,1.66),--\cdot,---$ \\
\hline
\end{tabular}

Table 5: MLEs, SEs and CIs for the data set III.

\begin{tabular}{|c|c|c|}
\hline Model & & $a, b, \alpha, \theta, \gamma$ \\
\hline \multirow[t]{3}{*}{$\mathrm{Lx}$} & MLEs & ---,---, ---, 0.392,--- \\
\hline & SEs & $---,---,---,(0.051),---$ \\
\hline & CIs & ---,---, ---, $(0.29,0.49),---$ \\
\hline \multirow[t]{3}{*}{ ExpLx } & MLEs & $---,---, 0.332,0.604,---$ \\
\hline & SEs & $---,---,(0.0405),(0.122),---$ \\
\hline & CIs & ---,---, $(0.25,0.41),(0.36,0.84),---$ \\
\hline \multirow[t]{3}{*}{ BXII } & MLEs & $---,---, 5.615,0.072,---$ \\
\hline & SEs & $---,---,(15.048),(0.194),---$ \\
\hline & CIs & $---,---,(0,35.11),(0,0.45),---$ \\
\hline \multirow[t]{3}{*}{ MOBXII } & MLEs & $---,---, 8.017,0.419,70.359$ \\
\hline & SEs & $---,---,(22.083),(0.312),(63.831)$ \\
\hline & CIs & $---,---,(0,51.29),(0,1.03),(0,195.47)$ \\
\hline \multirow[t]{3}{*}{ TLBXII } & MLEs & ---,---, 91.320, 0.012, 141.073 \\
\hline & SEs & $---,--,(15.071),(0.002),(70.028)$ \\
\hline & CIs &,,$------(61.78,120.86)(0.008,0.02)(3.82,278.33)$ \\
\hline \multirow[t]{3}{*}{ KumBXII } & MLEs & $18.130,6.857,10.694,0.081,---$ \\
\hline & SEs & $(3.689),(1.035),(1.166),(0.012),---$ \\
\hline & CIs & $(10.89,25.36),(4.83,8.89),(8.41,12.98),(0.06,0.10),---$ \\
\hline
\end{tabular}




\begin{tabular}{ccc} 
BBXII & MLEs & $26.725,9.756,27.364,0.020,---$ \\
& SEs & $(9.465),(2.781),(12.351),(0.007),---$ \\
BEBXII & CIs & $(8.17,45.27),(4.31,15.21),(3.16,51.57),(0.006,0.03),---$ \\
& MLEs & $2.924,2.911,3.270,12.486,0.371$ \\
& SEs & $(0.564),(0.549),(1.251),(6.938),(0.788)$ \\
FBBXII & CIs & $(1.82,4.03),(1.83,3.99),(0.82,5.72),(0,26.08),(0,1.92)$ \\
& MLEs & $(91.745),(1.064),(1.021),(8.268),(15.036)$ \\
& SEs & $(0,210.26),(0,2.67),(0,3.09),(0,21.37),(0,37.33)$ \\
FKumBXII & CIs & $12.878,1.225,1.665,1.411,3.732$ \\
& MLEs & $(3.442),(0.131),(0.034),(0.088),(1.172)$ \\
GOLLLx & SEs & $(6.13,19.6),(0.97,1.48),(1.56,1.73),(1.24,1.6),(1.43,6.03)$ \\
& CIs & $\mathbf{1 . 8 2 7}, \mathbf{2 3 . 1 2 9}, \mathbf{1 . 4 2},--,---$ \\
& MLEs & $(\mathbf{0 . 3 6 5}),(\mathbf{1 4 . 2 2}),(\mathbf{0 . 2 4 9}),-----$ \\
& SEs & $(\mathbf{1 . 1 , 2 . 5}),(\mathbf{0 , 5 1}),(\mathbf{0 . 9}, \mathbf{1 . 9}),--,---$ \\
\hline
\end{tabular}

Table 6: C-AI, C-Bayes, C-CA, C-HQ values for the data $\mathbf{I}$.

\begin{tabular}{cc}
\hline Model & C-AI, C-Bayes, C-CA, C-HQ \\
\hline Lx & $495.25,497.86,495.295,496.31$ \\
ExpLx & $470.39,475.59,470.51,472.49$ \\
BXII & $382.94,388.15,383.06,385.05$ \\
MOBXII & $305.78,313.60,306.03,308.96$ \\
TLBXII & $323.52,331.35,323.77,326.70$ \\
KumBXII & $303.76,314.21,304.18,308.00$ \\
BBXII & $305.64,316.06,306.06,309.85$ \\
BEBXII & $305.82,318.84,306.46,311.09$ \\
FBBXII & $304.26,317.31,304.89,309.56$ \\
FKumBXII & $305.50,318.55,306.14,310.80$ \\
GOLLLx & $\mathbf{3 0 1 . 4 4 , 3 0 9 . 2 6 , 3 0 1 . 6 9 , 3 0 4 . 6 1}$ \\
\hline
\end{tabular}

Table 7: C-AI, C-Bayes, C-CA, C-HQ values for the data II.

\begin{tabular}{cc}
\hline Model & C-AI, C-Bayes, C-CA, C-HQ \\
\hline LX & $283.18,285.45,283.23,284.08$ \\
ExpLx & $282.06,286.61,282.23,283.87$ \\
BXII & $209.60,214.15,209.77,211.40$ \\
MOBXII & $209.74,216.56,210.09,212.44$ \\
TLBXII & $211.80,218.63,212.15,214.52$ \\
KumBXII & $208.76,217.86,209.36,212.38$ \\
BBXII & $210.44,219.54,211.03,214.06$ \\
BEBXII & $212.10,223.50,213.00,216.60$ \\
FBBXII & $206.80,218.20,207.71,211.30$ \\
FKumBXII & $206.50,217.90,207.41,211.00$ \\
GOLLLx & $\mathbf{2 0 4 . 0 5 , 2 1 0 . 8 8 , 2 0 6 . 7 7 , 2 0 4 . 4 0 5}$ \\
\hline & \\
Table 7: C-AI, C-Bayes, C-CA, C-HQ values for the data III. \\
\hline Model & C-AI, C-Bayes, C-CA, C-HQ \\
\hline LX & $531.53,533.61,531.60,532.34$ \\
ExpLx & $397.92,402.08,398.13,399.01$ \\
BXII & $518.46,522.62,518.67,520.08$ \\
MOBXII & $387.22,389.38,387.66,389.68$ \\
TLBXII & $385.94,392.18,386.38,388.40$ \\
KumBXII & $385.58,393.90,386.32,388.86$ \\
BBXII & $385.56,394.10,386.30,389.10$
\end{tabular}




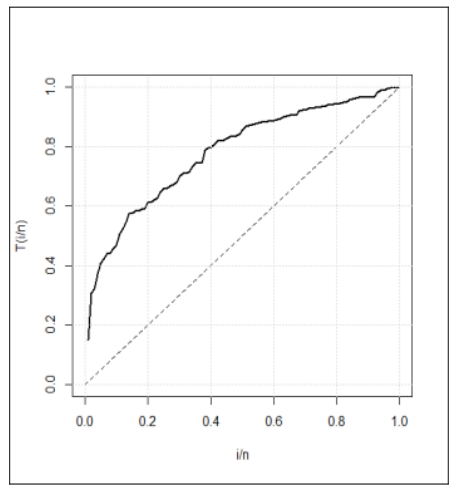

Data $\mathbf{I}$.

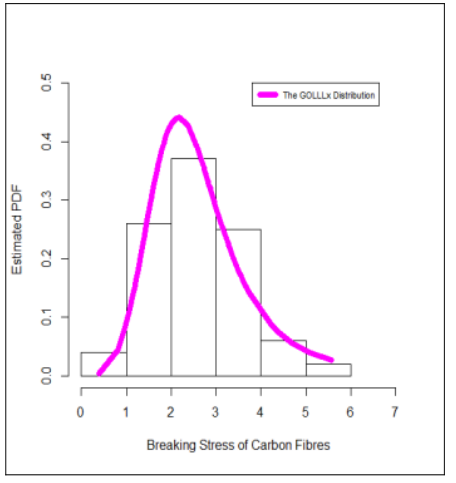

Data $\mathbf{I}$.

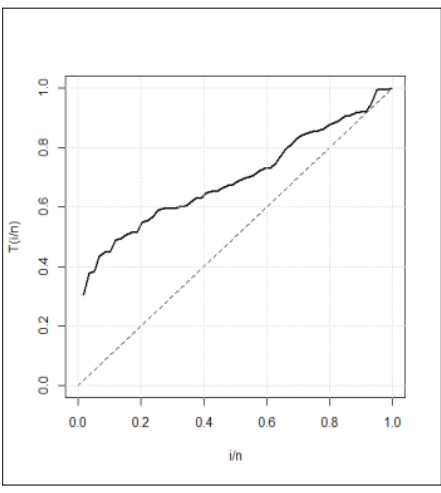

Data II.

Figure 3: TTT plots.

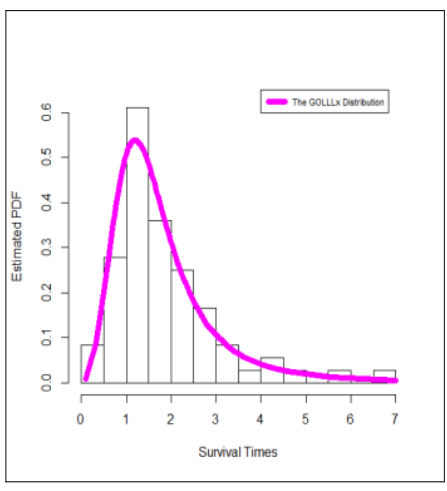

Data II.

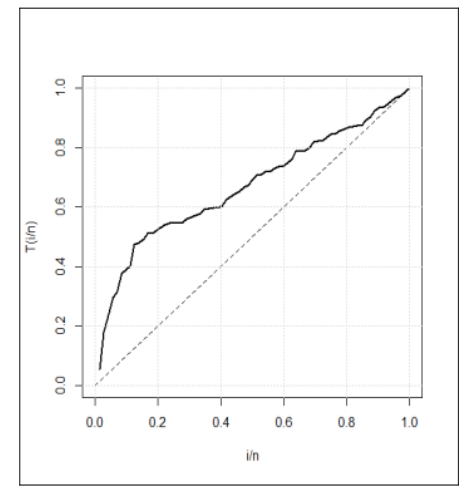

Data III.

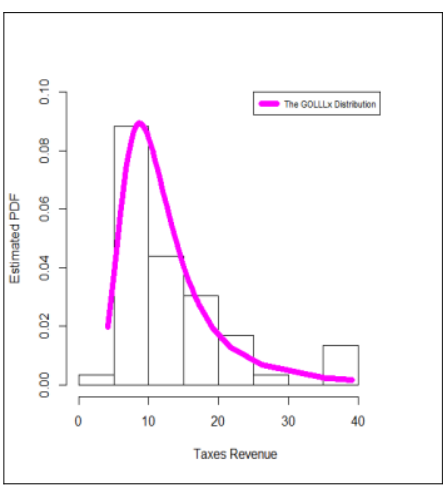

Data III.

Figure 4: Estimated PDFs. 


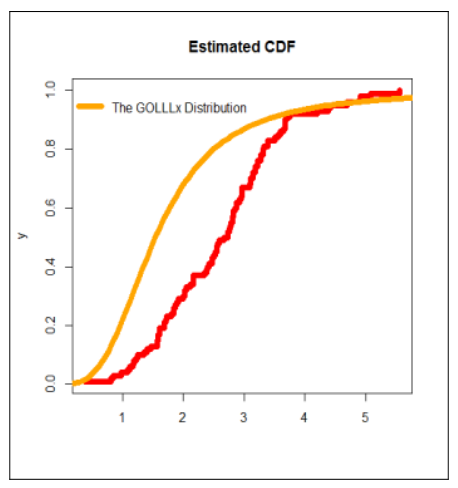

Data $\mathbf{I}$.

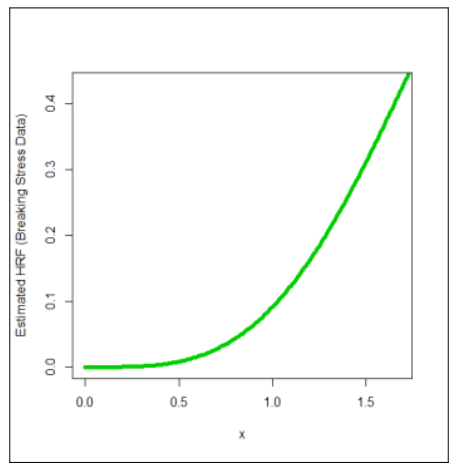

Data $\mathbf{I}$.

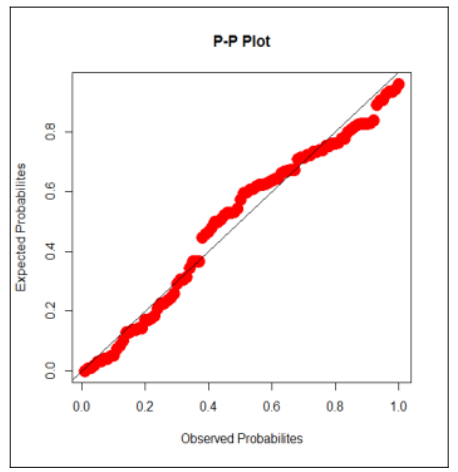

Data $\mathbf{I}$.

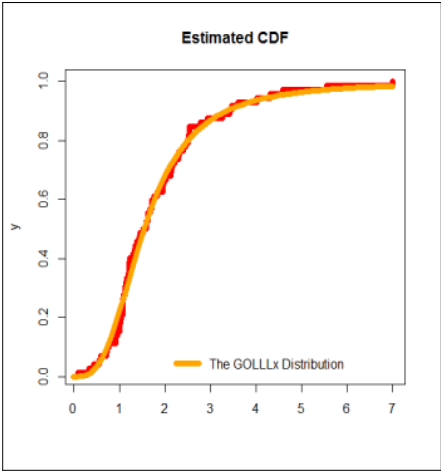

Data II.

Figure 5: Estimated CDFs.

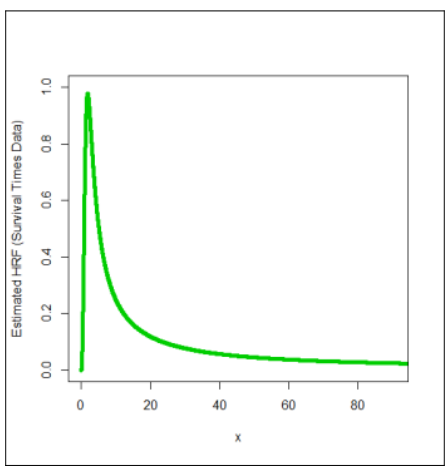

Data II.

Figure 6: Estimated HRFs.

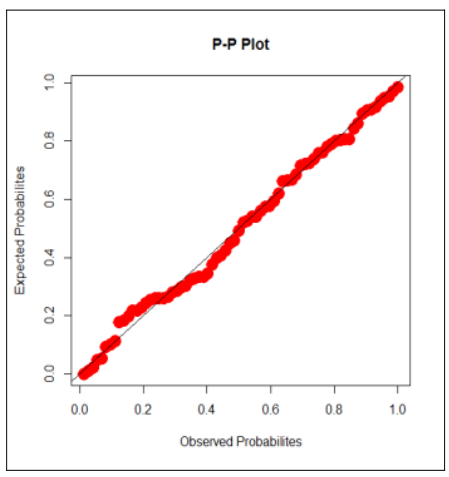

Data II.

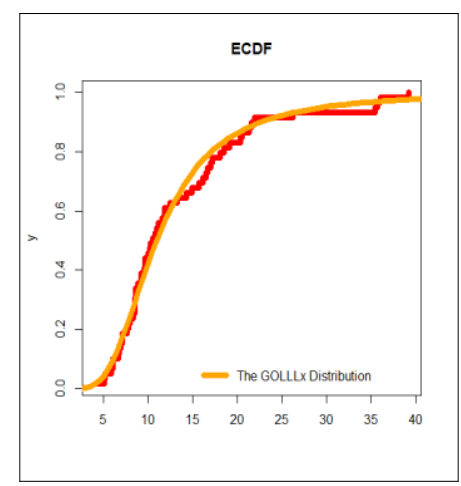

Data III.

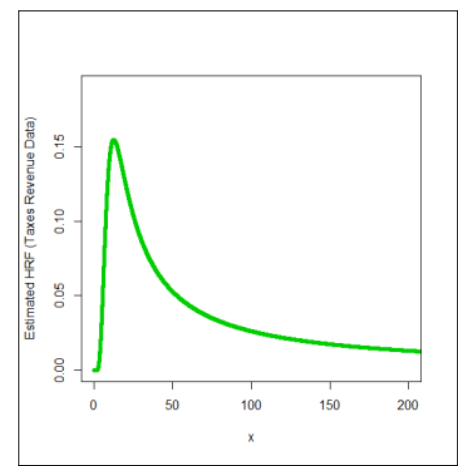

Data III.

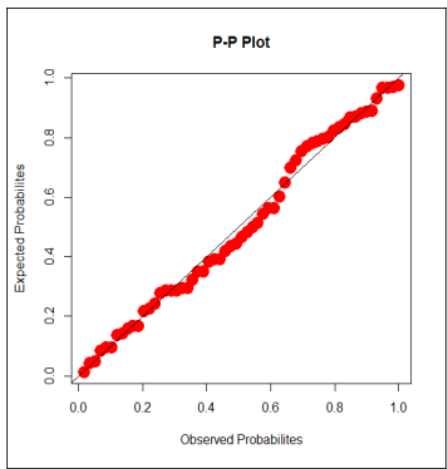

Data III.

Figure 7: P-P plots. 


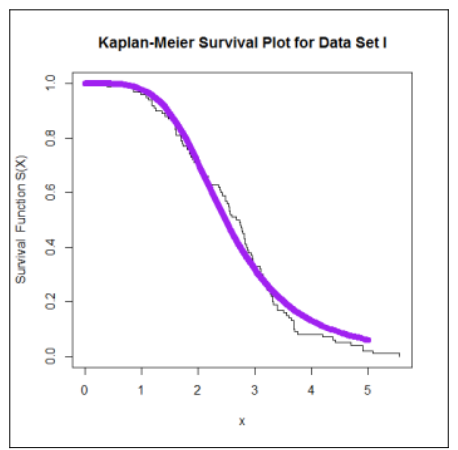

Data I.

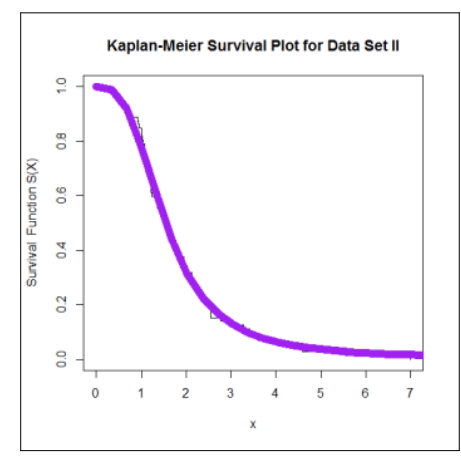

Data II.

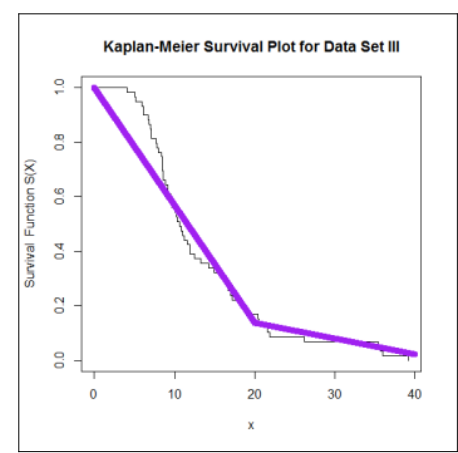

Data III.

Figure 8: Kaplan-Meier survival Plot.

\section{Conclusions}

A new generalization of Lomax distribution is derived and studied. The new extension has only three parameters. Some of its useful mathematical properties are derived. We performed graphical simulations to assess the finite sample behavior of the estimations. The effects of all parameters on the mean, variance, skewness and kurtosis for given values are studied. we note that the new additional shape parameters and has an effect on the mean, variance, skewness and kurtosis. For the new Lx model, skewness can range in the interval $(-183.1,7514.7)$. However, for the standard Lx model, skewness can range in the interval $(-0.4104,4.6476)$. For the GOLLLx model, kurtosis can range in the interval $(-1531.11,56479275)$. However, for the standard Lx model, kurtosis can range in the interval (0.93244, 73.8). The new model is employed in modelling three real data sets. For all data sets, we compared the new Lx distribution with the standard Lx, the exponentiated Lx, the Burr XII, beta Burr XII, the Marshall-Olkin Burr XII, the Topp-Leone Burr XII, the Zografos-Balakrishnan Burr XII, beta exponentiated Burr XII, the five-parameters beta Burr XII, the five-parameters Kumaraswamy Burr XII and Kumaraswamy Burr XII distributions. The new Lx distribution is a useful alternative for the above-mentioned models in modeling breaking stress data, survival times of guinea pig's data and the Egyptian taxes revenue data.

\section{References}

1. Altun, E., Yousof, H. M. and Hamedani, G. G. (2018). A new log-location regression model with influence diagnostics and residual analysis. Facta Universitatis, Series: Mathematics and Informatics, 33(3), 417-449

2. Altun, E., Yousof, H. M., Chakraborty, S. and Handique, L. (2018). Zografos-Balakrishnan Burr XII distribution: regression modeling and applications. International Journal of Mathematics and Statistics, 19(3), 46-70.

3. Ansari, S., Rezk, H. and Yousof, H. (2020). A new compound version of the generalized Lomax distribution for modeling failure and service times. Pakistan Journal of Statistics and Operation Research, 95-107.

4. Asgharzadeh, A. and Valiollahi, R. (2011). Estimation of the scale parameter of the Lomax distribution under progressive censoring, International Journal for Business and Economics 6, 37--48.

5. Bhatti, F. A., Hamedani, G., Yousof, H. M., Ali, A. and Ahmad, M. (2018). On Modified Burr XII-Inverse Exponential Distribution: Properties, Characterizations and Applications. J Biostat Biom: JBSB-106. DOI, 10.

6. Bjerkedal, T. (1960). Acquisition of resistance in Guinea pigs infected with different doses of virulent tubercle bacilli. American Journal of Hygiene, 72, 130--148.

7. Burr, I. W. (1942). Cumulative frequency functions. Annals of Mathematical Statistics, 13, 215-232.

8. Burr, I. W. (1968). On a general system of distributions, III. The simplerange. Journal of the American Statistical Association, 63, 636-643.

9. Burr, I. W. (1973). Parameters for a general system of distributions to match a grid of $\alpha_{3}$ and $\alpha_{4}$ .Communications in Statistics, 2, 1-21.

10. Burr, I. W. and Cislak, P. J. (1968). On a general system of distributions: I. Its curve-shaped characteristics; II. The sample median. Journalof the American Statistical Association, 63, 627-635.

11. Corbellini, A., Crosato, L., Ganugi, P and Mazzoli, M. (2007). Fitting Pareto II distributions on firm size: Statistical methodology and economic puzzles. Paper presented at the International Conference on Applied Stochastic Models and Data Analysis, Chania, Crete.

12. Cordeiro, G. M., Yousof, H. M., Ramires, T. G. and Ortega, E. M. M. (2018). The Burr XII system of densities: 
properties, regression model and applications. Journal of Statistical Computation and Simulation, 88(3), $432-456$.

13. Elbiely, M. M. and Yousof, H. M. (2018). A New Extension of the Lomax Distribution and its Applications, Journal of Statistics and Applications, 2(1), 18-34.

14. Elbiely, M. M. and Yousof, H. M. (2019). A New Inverse Weibull Distribution: Properties and Applications. Journal of Mathematics and Statistics, 15(1), 30-43.

15. Elsayed, H. A. and Yousof, H. M. (2019a). A new Lomax distribution for modeling survival times and taxes revenue data sets. Journal of Statistics and Applications, forthcoming.

16. Elsayed, H. A. H. and Yousof, H. M. (2019b). Extended Poisson generalized Burr XII distribution. Journal of Applied Probability and Statistics, forthcoming.

17. Elsayed, H. A. H. and Yousof, H. M. (2019c). The Burr X Nadarajah Haghighi distribution: statistical properties and application to the exceedances of flood peaks data. Journal of Mathematics and Statistics, 15, 146-157.

18. Elsayed, H. A. H. and Yousof, H. M. (2020). The generalized odd generalized exponential Fréchet model: univariate, bivariate and multivariate extensions with properties and applications to the univariate version. Pakistan Journal of Statistics and Operation Research, 16(3), 529-544.

19. Gad, A. M., Hamedani, G. G., Salehabadi, S. M. and Yousof, H. M. (2019). The Burr XII-Burr XII distribution: mathematical properties and characterizations. Pakistan Journal of Statistics, 35(3), 229-248.

20. Gelfand, A. E., and Smith, A. F. (1990). Sampling-based approaches to calculating marginal densities. Journal of the American statistical association, 85(410), 398-409.

21. Goual, H. and Yousof, H. M. (2019). Validation of Burr XII inverse Rayleigh model via a modified chi-squared goodness-of-fit test. Journal of Applied Statistics, 47(1), 1-32.

22. Goual, H., Yousof, H. M. and Ali, M. M. (2020). Lomax inverse Weibull model: properties, applications and a modified chi-squared goodness-of-fit test for validation. Journal of Nonlinear Science and Applications, forthcoming.

23. Gupta, R. C. and Gupta, R. D. (2007). Proportional reversed hazard rate model and its applications. J. Statist. Plan. Inference, 137, 3525-3536.

24. Hamedani G. G. Rasekhi, M., Najibi, S. M., Yousof, H. M. and Alizadeh, M., (2019). Type II general exponential class of distributions. Pak. J. Stat. Oper. Res., XV (2), 503-523.

25. Harris, C.M. (1968). The Pareto distribution as a queue service descipline, Operations Research 16, $307--313$.

26. Hassan, A.S. and Al-Ghamdi, A.S. (2009). Optimum step stress accelerated life testing for Lomax distibution, Journal of Applied Sciences Research 5, 2153--2164.

27. Ibrahim, M. and Yousof, H. M. (2020). A new generalized Lomax model: statistical properties and applications, Journal of Data Science, 18(1), 190 -- 217.

28. Ibrahim, M., Altun, E. and Yousof, H. M. (2020). A new distribution for modeling lifetime data with different methods of estimation and censored regression modeling. Statistics, Optimization and Information Computing, $8,610-630$.

29. Ibrahim, M., Yadav, A. S. Yousof, H. M., Goual, H. and Hamedani, G. G. (2019). A new extension of Lindley distribution: modified validation test, characterizations and different methods of estimation, Communications for Statistical Applications and Methods, 26(5), 473-495.

30. Karamikabir, H., Afshari, M., Yousof, H. M., Alizadeh, M., \& Hamedani, G. (2020). The Weibull Topp-Leone Generated Family of Distributions: Statistical Properties and Applications. Journal of The Iranian Statistical Society, 19(1), 121-161.

31. Korkmaz, M. C., Altun, E., Yousof, H. M. and Hamedani G. G. (2019). The odd power Lindley generator of probability distributions: properties, characterizations and regression modeling, International Journal of Statistics and Probability, 8(2), 70-89.

32. Korkmaz, M. C. Yousof, H. M. and Ali, M. M. (2017). Some theoretical and computational aspects of the odd Lindley Fréchet distribution, Journal of Statisticians: Statistics and Actuarial Sciences, 2, 129-140.

33. Korkmaz, M. C. Yousof, H. M. and Hamedani G. G. (2018). The exponential Lindley odd log-logistic G family: properties, characterizations and applications. Journal of Statistical Theory and Applications, 17(3), 554 - 571.

34. Merovci, F., Alizadeh, M., Yousof, H. M. and Hamedani G. G. (2017). The exponentiated transmuted-G family of distributions: theory and applications, Communications in Statistics-Theory and Methods, 46(21), 1080010822 .

35. Lomax, K.S. (1954). Business failures: Another example of the analysis of failure data, Journal of the American Statistical Association 49, 847-852.

36. Mansour, M. M., Butt, N. S., Ansari, S. I., Yousof, H. M., Ali, M. M., Ibrahim, M. (2020a). A new exponentiated Weibull distribution's extension: copula, mathematical properties and applications. Contributions

37. Mansour, M. M., Butt, N. S., Yousof, H., Ansari, S. I. and Ibrahim, M. (2020b). A Generalization of Reciprocal 
Exponential Model: Clayton Copula, Statistical Properties and Modeling Skewed and Symmetric Real Data Sets. Pakistan Journal of Statistics and Operation Research, 373-386.

38. Mansour, M. M., Ibrahim, M., Aidi, K., Shafique Butt, N., Ali, M. M., Yousof, H. M. and Hamed, M. S. (2020c). A New Log-Logistic Lifetime Model with Mathematical Properties, Copula, Modified Goodness-of-Fit test for Validation and Real Data Modeling. Mathematics, 8(9), 1508.

39. Mansour, M., Korkmaz, M. C, Ali, M. M., Yousof, H. M., Ansari, S. I. and Ibrahim, M. (2020d). A Generalization of the Exponentiated Weibull Model with Properties, Copula and Application. Eurasian Bulletin of Mathematics, 3(2), 84-102.

40. Mansour, M., Rasekhi, M., Ibrahim, M., Aidi, K., Yousof, H. M. and Elrazik, E. A. (2020e). A New Parametric Life Distribution with Modified Bagdonavičius--Nikulin Goodness-of-Fit Test for Censored Validation, Properties, Applications, and Different Estimation Methods. Entropy, 22(5), 592.

41. Mansour, M., Yousof, H. M., Shehata, W. A. and Ibrahim, M. (2020f). A new two parameter Burr XII distribution: properties, copula, different estimation methods and modeling acute bone cancer data. Journal of Nonlinear Science and Applications, , 13(5), 223-238.

42. Nichols, M.D. and Padgett, W.J. (2006). A bootstrap control chart for Weibull percentiles. Quality and Reliability Engineering International, 22, 141-151.

43. Rodriguez, R.N. (1977). A guide to the Burr type XII distributions. Biometrika, 64, 129--134.

44. Tadikamalla, P. R. (1980). A look at the Burr and related distributions, International Statistical Review, 48, 337 344.

45. Yadav, A.S., Goual, H., Alotaibi, R.M. Rezk, H., Ali, M.M. and Yousof, H.M. (2020). Validation of the ToppLeone Lomax model via a modified Nikulin-Rao-Robson goodness-of-fit test with different methods of estimation. Symmetry, 12, 1-26. doi: 10.3390/sym12010057

46. Yousof, H. M., Afify, A. Z., Alizadeh, M., Nadarajah, S., Aryal, G. R. and Hamedani, G. G. (2018a). The Marshall-Olkin generalized-G family of distributions with Applications, STATISTICA, 78(3), 273- 295.

47. Yousof, H. M., Altun, E., Ramires, T. G., Alizadeh, M. and Rasekhi, M. (2018b). A new family of distributions with properties, regression models and applications, Journal of Statistics and Management Systems, 21, 163-188.

48. Yousof, H. M., Altun, E., Rasekhi, M., Alizadeh, M., Hamedani, G. G. and Ali, M. M. (2019). A new lifetime model with regression models, characterizations and applications. Communications in Statistics-Simulation and Computation, 48(1), 264-286.

49. Yousof, H. M., Majumder, M., Jahanshahi, S. M. A., Ali, M. M. and Hamedani G. G. (2018c). A new Weibull class of distributions: theory, characterizations and applications, Journal of Statistical Research of Iran, 15, 4583. 